\title{
Riskli bebeklerde serebral palsiyi önleme yöntemleri
}

\author{
Prevention strategies of cerebral palsy in infant at risk
}

\author{
Abdullah Barış Akcan, Münevver Kaynak Türkmen \\ Aydın Adnan Menderes Üniversitesi Tıp Fakültesi, Çocuk Sağlığı ve Hastalıkları Ana Bilim Dalı, Neonatoloji Bilim Dalı, Aydın
}

\begin{abstract}
Serebral palsi, insanların hareket etme yeteneğini etkileyen bir grup durumu içeren bir terimdir ve çocukluk çağında en sık görülen fiziksel engeldir. Serebral palsi genellikle doğumdan önce, doğum sırasında veya sonrasında, bebeklerin gelişen beyinlerinde hasara yol açan olaylardan kaynaklanır. Serebral palsinin tek bir nedeni bilinmemektedir. Birçok çocuk için serebral palsinin nedeni belirsizdir, ancak birçok risk faktörü bilinmektedir. En büyük risk faktörü erken doğumdur. Yenidoğan dönemindeki diğer risk faktörleri arasında doğum sırasında uzun süreli oksijensizlik; beyin hasarı; stroke (inme) veya nöbetler; kalp, kan damarları, hava yolları ve akciğer patolojileri; uzun süreli mekanik ventilasyon, bazı enfeksiyonlar, hiperbilirubinemi, bazı sendromlar veya kromozom anormallikleri yer almaktadır. Serebral palsi için farklı risk faktörleri ve nedenleri olduğundan, risk faktörlerini azaltarak serebral palsiyi önlemek için farklı girişimlere gereksinim duyulmaktadır. Bu derleme, yenidoğan dönemindeki girişimlerle ilgili literatürde sunulan serebral palsinin önlenmesine ilişkin kanıtları özetlemektedir.
\end{abstract}

Anahtar sözcükler: serebral palsi; yenidoğan; prematüre; erken girişim

\section{SEREBRAL PALSi}

\section{Tanım}

Serebral palsi (SP), gelişen beyindeki bir anormallikten kaynaklanan ve yaşamın ilk yıllarında gelişen kas tonusu, postürü ve hareketini etkileyen ilerleyici olmayan motor bozuklukların varlığı ile karakterize bir klinik sendromdur. ${ }^{[1]} \mathrm{SP}$, genellikle doğumdan önce, doğum sırasında veya sonrasında bebeklerin gelişen beyinlerine zarar veren olaylardan kaynaklanır. SP'nin tek bir nedeni bilinmemektedir, ancak birçok risk faktörü bilinmektedir. En büyük risk faktörü erken doğumdur. SP, tüm gestasyon (gebelik)
Cerebral palsy is a term that includes a group of conditions that affect people's ability to move and is the most common physical disability in childhood. Cerebral palsy is usually caused by events that cause damage to the developing brains of babies before, during or after birth. No single cause of cerebral palsy is known. For many children, the cause of cerebral palsy is unclear, but many risk factors are known. The biggest risk factor is premature birth. Other risk factors in the neonatal period include prolonged lack of oxygen during delivery; brain injury; stroke or seizures; heart, blood vessels, airways and lung pathologies; prolonged mechanical ventilation, some infections, hyperbilirubinemia, and some syndromes or chromosomal abnormalities. Since there are different risk factors and causes for cerebral palsy, different interventions are needed to prevent cerebral palsy by reducing risk factors. This review summarizes the evidence for the prevention of cerebral palsy presented in the literature on interventions in the neonatal period.

Key words: cerebral palsy; newborn; prematurity; early intervention

haftalarında doğan bebeklerde görülen heterojen bir motor bozukluktur, ancak erken doğan bebeklerde daha yaygındır. ${ }^{[2]}$ Yenidoğan döneminde diğer risk faktörleri arasında doğum sırasında uzun süre oksijensiz kalma, beyin hasarı, stroke (inme) veya nöbetler, kardiyak patolojiler, akciğer kaynaklı problemler, uzun süre mekanik ventilatör desteği, bazı enfeksiyonlar, hiperbilirubinemi, bazı sendromlar veya kromozom anormallikleri sayılabilir.

\section{Sıklık}

Genel popülasyonda SP görülme sıklığı, dünya genelinde \%0,1 ile \%0,2 oranında değişmekte ancak

- Illetişim adresi: Doç. Dr. Abdullah Barış Akcan, Aydın Adnan Menderes Üniversitesi Tıp Fakültesi, Çocuk Sağlığı ve Hastalıkları Ana Bilim Dalı, Neonatoloji Bilim Dalı, Aydın, Türkiye Tel: 0256 - 2142040 e-posta: barisakc@hotmail.com

- Geliștarihi: 21 Șubat $2021 \quad$ Kabul tarihi: 6 Mart 2021 
gelişmekte olan ülkelerde biraz daha yüksek oranda görülmektedir. Gebelik haftası azaldıkça SP riski artmaktadır. ${ }^{3]}$ SP olgularının \%58'i 37. gebelik haftasında veya daha sonra doğan bebeklerde görülmesine rağmen, SP bu gestasyonel yaş grubunun sadece \%0,1'ini etkiler. Karşılaştırıldığında, çok erken doğumlar tüm SP olgularının \%25'ini oluşturur, ancak 32. gebelik haftasından önce doğanların \%8,7'si SP geliştirir. Gebelik haftaları 32 ila 37 arasında doğan bebekler, tüm SP olgularının \%17'sini oluşturur ve bu gebelik haftası aralığında doğanların \%3'ünde SP gelişiri. ${ }^{[4]}$ Erken doğumları azaltma çabaları, çok erken doğumla ilgili SP oranını düşürmüş, ancak bu önlemin SP'nin yaygınlığı üzerinde çok az etkisi olmuştur. Çünkü çok erken doğumlar tüm doğumların sadece $\% 2$ 'sini oluşturmaktadır. Sonuç olarak, perinatal bakımdaki gelişmelere rağmen SP sıklığı 1000 canlı doğumda 1,5 ile 2,5 olguda değişmeden kalmıştır. ${ }^{[3]}$

\section{Patoloji}

SP, gelişmekte olan beyinde doğum öncesi, doğum esnasında veya doğum sonrası dönemlerde meydana gelebilecek hasarlanmadan kaynaklanır. Intrapartum hipoksik iskemik zedelenme genellikle SP gelişimi ile ilişkilidir ve tüm olguların \%10 ile \%20'sini oluşturmaktadır. ${ }^{[5]}$ SP etiyolojisi multifaktöriyeldir (çok etmenlidir). 1986'dan 2003'e kadar SP tanısı almış 235 çocuğun kohort incelemesinde, SP ile ilişkili en yaygın klinik faktörler veya patolojiler prematürite (\%78), intrauterin büyüme kısıtlılığı (\%34), intrauterin enfeksiyon (\%28), antepartum kanama (\%27) ve çoğul gebelik (\%20) olarak bildirilmiştir. ${ }^{[6]}$

\section{Önleme}

Erken doğumun önlenmesi, antenatal kortikosteroid uygulanması, geç kord klemplenmesi gibi uygulamaların daha sonra gelişebilecek SP için artmış risk ile ilişkili olan prematürite, intraventriküler hemoraji (IVH), periventriküler lökomalazi (PVL) riskini çeşitli şekillerde azalttığı gösterilmiştir. ${ }^{[7,8]}$ Diğer taraftan, sürekli fetal kalp hızı izlemi gibi hipoksik iskemik ensefalopatiyi ve sonuçta ortaya çıkan SP'yi azaltmayı amaçlayan girişimlerin yararlı olduğu gösterilememiştir. ${ }^{[9]}$

\section{Magnezyum Sülfat}

Magnezyum sülfat, vasküler tonusu stabilize edebilir, reperfüzyon hasarını ve sitokin aracılı hasarı azaltabilir ve hayvan modellerinde nöronal hasarı iyileştirebilir. ${ }^{[10]}$ Farklı randomize çalışmalar, 24 saat içinde erken doğum riski olan annelere magnezyum sülfat uygulanmasının, erken doğan bebeklerde kaba motor işlev bozukluğunu veya SP'yi azalttı̆̆ göstermiştir. ${ }^{[11-13]}$ Rouse ve ark. ile NICHD Maternal-Fetal Tip Birimi tarafından yapılan bir çalışmada, 32. gebelik haftasından önce preterm doğum riski olan annelere antenatal magnezyum sülfat uygulaması ile orta veya şiddetli SP oranında anlamlı bir düşüş olduğu gösterilmiştir (RR, 0,55; \%95 Cl, 0,32-0,95). [13] Beş randomize kontrollü çalışmanın meta-analizi, SP'de (RR, 0,70; $\% 95 \mathrm{Cl}$, $0,55-0,89$ ) ve orta ile şiddetli SP'de (RR, 0,$60 ; \% 95 \mathrm{Cl}$, $0,43-0,84)$ istatistiksel olarak anlamlı bir düşüş olduğunu ortaya koymuştur. ${ }^{[14]}$ Bu bulgular ayrıca altı randomize, kontrollü çalışma ve beş kohort çalışmasının 2016 meta-analizi ile desteklenmiştir. Bu meta-analiz 18,655 prematüre bebeği içermekte ve orta ile şiddetli SP'de istatiksel olarak anlamlı bir düşüşü göstermiştir (OR, 0,61; \%95 Cl, 0,42-0,89).. ${ }^{[15]}$ Maternal-Fetal Medicine Topluluğu tarafindan desteklenen American College of Obstetricians and Gynecologist (ACOG), 2016 yılında 32. gebelik haftasından önce beklenen erken doğum olgularında magnezyum sülfatın bir fetal nöroprotektif ajan olarak kullanılması konusundaki önerilerini tekrarlamıştır. ${ }^{[16]}$

\section{Kafein}

Prematüre apnesi için kafein alan, 500 ile 1250 gram ağırlığında doğan yenidoğanlarda kafeinin etkinliği ve güvenliği bir çalışmada gösterilmiştir. ${ }^{[17]}$ Bu bebeklerin 18-21 aylık takiplerinde, kafeinin nörogelişimsel yetersizlik olmaksızın hayatta kalma oranını iyileştirdiği (OR, 0,77; \%95 Cl, 0,64-0,93), SP (OR, 0,58; \%95 $\mathrm{Cl}, 0,39-0,87)$ ve bilişsel gecikme (OR, 0,$81 ; \% 95 \mathrm{Cl}$, 0,66-0,99) sıklığını düşürdüğü gösterilmiştir. ${ }^{[18]}$ On bir yıllık takipte, kafeinin motor bozukluk riskini azalttığı (OR, 0,66; $95 \% \mathrm{Cl}, 0,48-0,9)$ ancak SP oranında veya ciddiyetinde anlamlı bir azalma sağlamadığı başka bir çalışmada gösterilmiştir. ${ }^{[19]}$

Çoğu çocukta SP'nin tipine ve ciddiyetine bağlı olarak, SP tanısı yaşamın ilk iki yılı içinde konur. ${ }^{[20]}$ Yapılan çalışmalarda SP'li çocuklarda ağrı, zihinsel engel, epilepsi, davranış bozuklukları, bağırsak ve mesane kontrol sorunları, konuşma ve dil bozuklukları, işitme bozukluğu gibi nörogelişimsel veya duyusal bozukluklar görülmektedir. SP’nin yönetimi, büyük ölçüde destekleyici olan ve durumdan etkilenenlerin yaşam kalitesini iyileştirmeyi amaçlayan multidisipliner bir yaklaşımı gerektirir. Hastaların yaklaşık \%90'ı yetişkinliğe kadar hayatta kalsa da, ciddi engelli olanlar erken çocukluk döneminde, çoğunlukla aspirasyon pnömonisi ve solunum hastalıklarından ölebilmektedir. ${ }^{[21]}$ Yakın zamanda yapılan bir meta-analizde serebral palsi hakkında neonatal dönemdeki girişimleri değerlendiren 43 Cochrane derlemesi incelenmiştir. ${ }^{[22]}$ Bu incelemelerin hepsi orta ve yüksek kalitede olup, ancak serebral palsi ile ilgili kanıtların kalitesi çok düşükten yükseğe değişmektedir. SP'nin önlenmesi için bir girişimin etkili 
olduğu bu meta-analizde tespit edilmiştir. Perinatal asfiksi gelişen yenidoğan bebeklerde terapötik hipotermi tedavisi uygulanan bebeklerin (tüm vücut soğutma veya baş soğutma), terapötik hipotermi uygulanmayan bebeklere göre serebral palsi gelişme olasılığı daha düşük bulunmuştur. ${ }^{[22-25]}$ Serebral palsinin önlenmesi için muhtemelen etkili olabilecek bir girişim daha bu meta-analizde gösterilmiştir. Solunum cihazı destekli solunumdan ayrılma (mekanik ventilasyondan ekstübasyon) planlandığında metilksantin (kafein) alan erken doğan yenidoğanlarda, plasebo alan bebeklere göre serebral palsi gelişme olasılığı daha düşük tespit edilmiştir. ${ }^{[22,26]}$ Muhtemelen etkisiz olan ve zarar verebilecek bir girişim de bu meta-analizde vurgulanmıştır. Kronik akciğer hastalığını önlemek için erken (sekiz günden daha kısa) kortikosteroid uygulanan preterm yenidoğanlarda, plasebo alan bebeklere göre uzun dönem takiplerinde serebral palsi geliştirme olasılıklarının arttığı dikkati çekmiştir. ${ }^{[22,27]}$

Son yirmi yılda, obstetrik ve pediatrik bakımdaki gelişmeler ve değişiklikler, çok erken doğan bebeklerin hayatta kalma ve nörogelişimsel sonuçlarının iyileşmesini sağlamıştır. Antenatal kortikosteroidlerin daha yaygın kullanımı, gecikmiş kordon klemplenmesi ve maternal magnezyum sülfat uygulaması IVH, PVL ve SP riskini azaltmıştır. ${ }^{[7,8,14]}$ Term bebeklerde, terapötik hipotermi, mekanik ventilasyon stratejilerindeki değişiklikler ve Eritropoetin (Epo) uygulaması gibi doğum sonrası girişimler daha da iyileştirilmiş sonuçlar elde edilmesine yol açmıştır. ${ }^{[28,29]}$

Bu gelişmelere rağmen, perinatal beyin hasarı, uzun vadeli nörogelişimsel engelliliğin önemli bir nedeni olmaya devam etmektedir. Uzun vadeli sonuçları iyileştirmeye devam etmek için perinatal beyin hasarının çeşitli mekanizmalarının çeşitli yönlerini hedefleyen yeni terapötik stratejiler üzerine araştırma yapılması gerekmektedir. Mezenkimal kök hücrelerin maternal uygulaması, sitokin inhibitör tedavisi ve maternal progesteron tedavisi, hayvan modellerinde umut vaat eden çalışmalardır. Preterm doğumu önlemek için çift kör, randomize, plasebo kontrollü bir vajinal progesteron çalışması olan 2016 OPPTIMUM (Preterm doğum için vajinal progesteron profilaksisi) çalışmasında, progesteron grubunda ultrason muayenesinde plaseboya kıyasla daha düşük beyin hasarı riski bulunmuştur (OR, 0,50; \%95 Cl, 0,31-0,84). ${ }^{[30]}$ Perinatal beyin hasarının yalnızca prematüriteye veya hipoksiiskemiye ikincil olmadığı, aynı zamanda bu olaylara yanıt olarak hem antenatal hem de postnatal enflamasyon tarafindan tetiklenen, altta yatan karmaşık bir hücresel ve immunolojik faktörü de içerdiğinin anlaşılması, yeni tedavi stratejilerinin keşfi için çok önemlidir.
Sonuç olarak teknolojik gelişme ve artan deneyim, daha küçük çocukların kurtarılmasına ve prematüre yenidoğanlarda tipik komplikasyonların etkili bir şekilde önlenmesine ve tedavisine yardımcı olmuştur. Yukarıda özetlenen girişimlerin, çocuklarda SP riski üzerinde kanıtlanmış veya potansiyel olarak koruyu$\mathrm{cu}$ etkileri vardır. Girişim grubunda SP insidansının azalmasını değerlendirmek için doğrudan çalışmalar olmasa da, girişimlerin her doğum öncesi ve doğum sonrası bakım servisindeki iyi tıbbi uygulamaların bir parçası olması gerektiğine dair hiçbir şüphemiz yoktur.

\section{KAYNAKLAR}

1. Blair E. Epidemiology of the cerebral palsies. Orthop Clin North Am 2010;41(4):441-55. Crossref

2. Stavsky M, Mor O, Mastrolia SA, Greenbaum S, Than NG, Erez O. Cerebral Palsy-Trends in Epidemiology and Recent Development in Prenatal Mechanisms of Disease, Treatment, and Prevention. Front Pediatr 2017;5:21. Crossref

3. Oskoui M, Coutinho F, Dykeman J, Jetté N, Pringsheim T. An update on the prevalence of cerebral palsy: a systematic review and meta-analysis. Dev Med Child Neurol 2013;55(6):50919. Crossref

4. Hirvonen M, Ojala R, Korhonen P, Haataja P, Eriksson K, Gissler M, Luukkaala T, Tammela O. Cerebral palsy among children born moderately and late preterm. Pediatrics 2014;134(6):e1584-93. Crossref

5. Executive summary: Neonatal encephalopathy and neurologic outcome, second edition. Report of the American College of Obstetricians and Gynecologists' Task Force on Neonatal Encephalopathy. Obstet Gynecol 2014;123(4):896-901. Crossref

6. Strijbis EM, Oudman I, van Essen P, MacLennan AH. Cerebral palsy and the application of the international criteria for acute intrapartum hypoxia. Obstet Gynecol 2006;107(6):1357-65. Crossref

7. Roberts D, Brown J, Medley N, Dalziel SR. Antenatal corticosteroids for accelerating fetal lung maturation for women at risk of preterm birth. Cochrane Database Syst Rev 2017;3(3):CD004454. Crossref

8. Committee on Obstetric Practice. Committee Opinion No 684: Delayed Umbilical Cord Clamping After Birth. Obstet Gynecol 2017;129(1):e5-10. Crossref

9. Alfirevic Z, Devane D, Gyte GM. Continuous cardiotocography (CTG) as a form of electronic fetal monitoring (EFM) for fetal assessment during labour. Cochrane Database Syst Rev 2017;3;2(2):CD006066. Crossref

10. Burd I, Breen K, Friedman A, Chai J, Elovitz MA. Magnesium sulfate reduces inflammation-associated brain injury in fetal mice. Am J Obstet Gynecol 2010;202(3):292.e1-9. Crossref

11. Crowther CA, Hiller JE, Doyle LW, Haslam RR; Australasian Collaborative Trial of Magnesium Sulphate (ACTOMg SO4) Collaborative Group. Effect of magnesium sulfate given for neuroprotection before preterm birth: a randomized controlled trial. JAMA 2003;290(20):2669-76. Crossref

12. Marret S, Marpeau L, Zupan-Simunek V, Eurin D, Lévêque C, Hellot M-F, Bénichou J. PREMAG trial group. Magnesium sulphate given before very-preterm birth to protect infant brain: the randomised controlled PREMAG trial. BJOG 2007;114(3):310-8. Crossref 
13. Rouse DJ, Hirtz DG, Thom E, Varner MW, Spong CY, Mercer BM, lams JD, Wapner RJ, Sorokin Y, Alexander JM, Harper M, Thorp JM Jr, Ramin SM, Malone FD, Carpenter M, Miodovnik M, Moawad A, O'Sullivan MJ, Peaceman AM, Hankins GDV, Langer O, Caritis SN, Roberts JM, Shriver EK; NICHD Maternal-Fetal Medicine Units Network. A randomized, controlled trial of magnesium sulfate for the prevention of cerebral palsy. N Engl J Med 2008;359(9):895-905. Crossref

14. Costantine MM, Weiner SJ; Eunice Kennedy Shriver National Institute of Child Health and Human Development (NICHD) Maternal-Fetal Medicine Units Network (MFMU). Effects of antenatal exposure to magnesium sulfate on neuroprotection and mortality in preterm infants: a meta-analysis. Obstet Gynecol 2009;114(2 Pt 1):354-64. Crossref

15. Zeng X, Xue Y, Tian Q, Sun R, An R. Effects and Safety of Magnesium Sulfate on Neuroprotection: A Meta-analysis Based on PRISMA Guidelines. Medicine (Baltimore) 2016;95(1):e2451. Crossref

16. The American College of Obstetricians and Gynecologists Committee on Obstetric Practice; Society for Maternal-Fetal Medicine. Committee Opinion No 455: Magnesium sulfate before anticipated preterm birth for neuroprotection. Obstet Gynecol 2010;115(3):669-71. Crossref

17. Schmidt B, Roberts RS, Davis P, Doyle LW, Barrington KJ, Ohlsson A, Solimano A, Tin W; Caffeine for Apnea of Prematurity Trial Group. Caffeine therapy for apnea of prematurity. N Engl J Med 2006;354(20):2112-21. Crossref

18. Schmidt B, Roberts RS, Davis P, Doyle LW, Barrington KJ, Ohlsson A, Solimano A, Tin W; Caffeine for Apnea of Prematurity Trial Group. Long-term effects of caffeine therapy for apnea of prematurity. N Engl J Med 2007;357(19):1893902. Crossref

19. Schmidt B, Roberts RS, Anderson PJ, Asztalos EV, Costantini L, Davis PG, Dewey D, D'llario J, Doyle LW, Grunau RE, Moddemann D, Nelson H, Ohlsson A, Solimano A, Tin W. Caffeine for Apnea of Prematurity (CAP) Trial Group. Academic Performance, Motor Function, and Behavior 11 Years After Neonatal Caffeine Citrate Therapy for Apnea of Prematurity: An 11-Year Follow-up of the CAP Randomized Clinical Trial. JAMA Pediatr 2017;171(6):564-72. Crossref

20. Granild-Jensen JB, Rackauskaite G, Flachs EM, Uldall P. Predictors for early diagnosis of cerebral palsy from national registry data. Dev Med Child Neurol 2015;57(10):931-5. Crossref

21. Novak I, Hines M, Goldsmith S, Barclay R. Clinical prognostic messages from a systematic review on cerebral palsy. Pediatrics 2012;130(5):e1285-312. Crossref
22. Shepherd E, Salam RA, Middleton P, Han S, Makrides M, Mclntyre S, Badawi N, Crowther CA. Neonatal interventions for preventing cerebral palsy: an overview of Cochrane Systematic Reviews. Cochrane Database Syst Rev 2018;6(6):CD012409. Crossref

23. Jacobs SE, Berg M, Hunt R, Tarnow-Mordi WO, Inder TE, Davis PG. Cooling for newborns with hypoxic ischaemic encephalopathy. Cochrane Database Syst Rev 2013;2013(1):CD003311. Crossref

24. Hunt R, Hey E. Ethamsylate for the prevention of morbidity and mortality in preterm or very low birth weight infants. Cochrane Database Syst Rev 2010;(1):CD004343. Crossref

25. Smit E, Odd D, Whitelaw A. Postnatal phenobarbital for the prevention of intraventricular haemorrhage in preterm infants. Cochrane Database Syst Rev 2013;2013(8):CD001691. Crossref

26. Henderson-Smart DJ, Davis PG. Prophylactic methylxanthines for endotracheal extubation in preterm infants. Cochrane Database Syst Rev 2010;(12):CD000139. Crossref

27. Doyle LW, Cheong JL, Ehrenkranz RA, Halliday HL. Early $(<8$ days) systemic postnatal corticosteroids for prevention of bronchopulmonary dysplasia in preterm infants. Cochrane Database Syst Rev 2017;10(10):CD001146. Crossref

28. Shankaran S, Laptook AR, Ehrenkranz RA, Tyson JE, McDonald SA, Donovan EF, Fanaroff AA, Poole WK, Wright LL, Higgins RD, Finer NN, Carlo WA, Duara S, Oh W, Cotten CM, Stevenson DK, Stoll BJ, Lemons JA, Guillet R, Jobe AH; National Institute of Child Health and Human Development Neonatal Research Network. National Institute of Child Health and Human Development Neonatal Research Network. Whole-body hypothermia for neonates with hypoxic-ischemic encephalopathy. N Engl J Med 2005;353(15):1574-84. Crossref

29. Wyatt JS, Gluckman PD, Liu PY, Azzopardi D, Ballard R, Edwards AD, Ferriero DM, Polin RA, Robertson CM, Thoresen M, Whitelaw A, Gunn AJ; CoolCap Study Group. Determinants of outcomes after head cooling for neonatal encephalopathy. Pediatrics 2007;119(5):912-21. Crossref

30. Norman JE, Marlow N, Messow CM, Shennan A, Bennett PR, Thornton S, Robson SC, McConnachie A, Petrou S, Sebire NJ, Lavender T, Whyte S, Norrie J; OPPTIMUM study group. Vaginal progesterone prophylaxis for preterm birth (the OPPTIMUM study): a multicentre, randomised, double-blind trial. Lancet 2016;387(10033):2106-16. Crossref 